The Journal of Animal \& Plant Sciences, 31(1): 2021, Page: 70-76

ISSN (print): 1018-7081; ISSN (online): 2309-8694

\title{
EVALUATION OF SERUM CHOLINE ALONG WITH, SOME BIOCHEMICAL AND CLINICAL PARAMETERS IN CATTLE SUFFERING FROM WITH BOTULISM
}

\author{
H. Batmaz ${ }^{1 *}$, Z. Mecitoğlu ${ }^{1}$, C. Koç², F. Kaya ${ }^{1}$, O. Topal ${ }^{1}$ and M. Cansev ${ }^{2}$ \\ ${ }^{1}$ Bursa Uludag University, Faculty of Veterinary Medicine, Department of Internal Medicine \\ ${ }^{2}$ Bursa Uludag University, Faculty of Medicine, Department of Pharmacology \\ *Corresponding Author's e-mail: hbatmaz@uludag.edu.tr
}

\begin{abstract}
Botulism is a disease of cattle that causes significant impact due to its high mortality rate. The aim of the present study is to evaluate serum choline levels as well as clinical and biochemical parameters of cattle suspected to be suffering from botulism and to compare the results with healthy cattle and also to compare the results of survivors and fatalities. Thirteen botulism suspected and eleven healthy cattle were used. Total protein, albumin, aspartate aminotransferase (AST), alanine aminotransferase (ALT), gamma glutamyl transferase (GGT), calcium, phosphorus, magnesium and potassium levels were measured from the sera of botulism and control cattle by colorimetric method using an autoanalyser. Choline levels were analyzed using HPLC. Dysphagia, decreased tongue strength weak anal reflexes, tongue and tail paralysis and locomotion disorders were the main clinical findings observed in suspected botulism cases. Botulinum toxin analysis of ruminal fluid samples were positive in two cattle from one herd. AST, ALT, potassium and choline levels were higher in cattle suffering from suspected botulism cases and choline levels were positively correlated with albumin and total protein levels. Three animals from botulism group survived. Clinical findings were milder, animals were not recumbent and choline levels were lower in survivors. Clinical findings of the three animals that recovered were milder, animals were not recumbent and choline levels were lower in survivors. It was observed that clinical findings such as decreased tongue strength and anal reflexes, dysphagia, tail paralysis, and locomotion disorders are important for diagnosis of botulism In conclusion, cattle with milder clinical signs and lower choline have a higher chance of survival.
\end{abstract}

Keywords: Botulism, choline, biochemical parameters, clinical findings.

https://doi.org/10.36899/JAPS.2021.1.0194

Published online August 26, 2020

\section{INTRODUCTION}

Botulism is a disease of a wide range of species characterized with flaccid paralysis and high mortality. Botulism is a worldwide problem of cattle and causes significant economic impact due to its high mortality rate (Radostits et al., 2007). The disease is caused by botulinum neurotoxins (BoNT) produced by Clostridium spp. There are seven known serotypes of BoNT (A, B, C, D, E, F and G) produced by three different species of clostridia (Cl. barati, $\mathrm{Cl}$. butyricum and Cl. botulinum) (Popoff, 2014). Only BoNT types B, $\mathrm{C}$ and $\mathrm{D}$ have been shown to produce disease in cattle, therefore $\mathrm{Cl}$. botulinum which is the only species capable of producing these three types of toxins is the main actor of the disease in cattle (Galey et al., 2000; Otter et al., 2006; Senturk and Cihan, 2007). Eating carrion, contamination of feedstuff and especially silage with carcasses, feeding cattle with poultry litter; improper use of poultry litter in pastures are reported causes of botulism in cattle (Galey et al.,2000; Yeruham et al., 2003). The main action of BoNT is to prevent the fusion of synaptic vesicles with the plasma membrane of nerve endings resulting in halting the release of neurotransmitter substances, in particular acetylcholine from the axon endings (Simpson, 2004). Halted neurotransmitter release causes flaccid paralysis which is characterized with clinical findings such as sudden paralysis starting from hind limbs affecting also the tail, inability to retract tongue and recumbency in later stages (Radostits et al., 2007). Detection of BoNT in serum or the abomasal, ruminal and intestinal contents of a suspected animal by mouse bioassay is the gold standard test for the diagnosis of botulism (Scarlatos et al., 2005). In addition to the mouse bioassay, serological detection of BoNT using a monoclonal antibody-based sandwich ELISA is a method used for diagnosis of the disease, however the diagnostic value of this method is questionable as there is not enough time for antibody formation especially in peracute cases (Mawhinney et al., 2012). Unfortunately, definitive diagnosis of botulism cases is not possible in every instance because the disease could be caused by extremely low levels of the toxin and the source of the toxin may be absent (Galey et al., 2000).

Choline is a vitamin-like essential nutrient which is essential for integrity of cell membranes, transmembrane signaling and brain development (Blusztajn, 1998). As well as that, choline is also the precursor of the cholinergic 
neurotransmitter, acetylcholine (Wurtman et al., 2009). Dietary intake, hepatic synthesis and hydrolysis of cell membrane phospholipids are the main sources of choline (Zeisel, 1992). Cohen and Wurtman (1975) reported that administration of choline elevates brain choline and acetylcholine levels. In another study, Cohen and Wurtman (1976) reported that administration of acetylcholinesterase inhibitor physostigmine resulted in increased brain acetylcholine levels and concluded that circulating choline is a factor controlling the brain acetylcholine levels. As mentioned above, effects of BoNT are associated with halting the acetylcholine from nerve endings. Habermann et al. (1981) reported that BoNT-A inhibits choline uptake of synaptosomes.

Hence, the aim of the present study was to investigate circulating choline levels as well as various biochemical parameters and clinical findings in cattle suffering from botulism and compare the results with healthy cattle. The other objective of the study was evaluation of clinical and biochemical findings of cattle surviving botulism.

\section{MATERIALS AND METHODS}

The material of the study consisted of 13 cattle from four different herds (7 Jersey and 6 HolsteinFresian), aged between 5 months to 5 years suspected of suffering from botulism. Age matched 11 cattle (6 Holstein-Fresian, 5 Jersey) were used as the control group. Of the 13 cattle in the botulism group, 7 of the cattle suffering from botulism were detected in farm A, 3 in farm B, 2 cattle from herd $\mathrm{C}$ and one cattle 1 from herd $\mathrm{D}$ and were brought to Uludag University Veterinary Clinics Animal Hospital.

In herd $\mathrm{A}$, it was reported that 3 cattle showing clinical signs such as stagnation, difficulty walking, hyper salivation and fullness of the rumen died within three days. In this herd of thirty Jersey cows, it was noticed that the silage was spoiled. Body temperature, heart and respiration rates, ruminal motility, general condition and walking patterns were evaluated as routine clinical examination in this and other herds. Botulism was suspected due to the history and the clinical appearance they showed, thus neurological evaluations such as tongue tone, swallowing, tail tone and anal reflexes were performed and seven animals that were found to show signs consistent with botulism were enrolled to the study

In an operation where three patients were identified (Herd B), one animal had a distinctly weak tongue tone, while the other two animals had a long retraction time when the tongue was pulled out. Three heifers were housed free in a field of about 20 acres in a group of 180 animals and there were no problems in the other animals. It was reported that a dead fox was found in that pen and removed by employees a few days ago.

Two one-year-old heifers from herd $\mathrm{C}$ were brought to our clinics with findings such as hyper salivation, severe dehydration and dysphagia. The owner reported that spoiled silage had been used for feeding the animals prior to this.

A five-month-old male calf was brought to our clinic with a complaint of recumbency and dysphagia for about a week (Herd D). It was reported that last year 21 cattle had died in the same farm, showing similar signs such as recumbency and tail paralysis. Poultry was very common in the area, and cattle could have eaten poultry litter in pasture.

All animals received 5-10 liters of electrolyte solution (5\% dextrose, isotonic sodium chloride and lactated Ringer's sol.) IV for daily rehydration and elimination of toxins. Six animals were drenched with 7-20 liters of water. Parenteral antibiotics were administered to prevent aspiration pneumonia. In addition, two animals from herd $\mathrm{A}$ recieved received neostigmine for 2 days at a dose of $0.025 \mathrm{mg} / \mathrm{kg}$ (Peristor, Provet Inc., Istanbul).

B ochem cal Analys s: Blood samples were collected from all the animals used in the study at the time of their first clinical examination. Samples from the control group were collected at the same time from age matched animals from the vena jugularis, after clotting at room temperature samples were centrifuged at $3000 \mathrm{rpm}$ for 15 minutes. Blood sera obtained were was stored at $-20^{\circ} \mathrm{C}$ until analysis. Total protein, albumin, aspartate aminotransferase (AST), alanine aminotransferase (ALT), gamma glutamyl transferase (GGT), calcium, phosphorus, magnesium and potassium levels were measured from sera of botulism and control cattle by means of the colorimetric method using an autoanalyser (Cobas 8000, Roche, Germany). Choline levels were analyzed using HPLC equipped with an enzymatic column and electrochemical detector (Hewlett Packard, Palo Alto, CA, USA) as reported previously (Cansev et al., 2015). The mobile phase consisted of $0.5 \mathrm{M}$ $\mathrm{NaH} 2 \mathrm{PO} 4$ (pH 8.5).

Tox $\backsim$ Analys s: Rumen contents of ill animals and were collected at the time animals were first examined via stomach tube and along with suspected feed samples from four herds were sent to the Pendik Veterinary Control Research Institute for botulism toxin analysis by mouse bioassay.

Stat st cal Analys s: Statistical analysis of the results was performed using SigmaPlot 12 software (Systat Software Inc., USA). A normality test was performed using the Shapiro-Wilk test and the data was found to be normally distributed. Choline and the other biochemical parameters were compared by using students student's t-test. Correlations between the parameters were quantified by 
Pearson's correlation coefficients. For all analyses, P $<0.05$ was considered significant.

\section{RESULTS}

Suspected sources of toxin were spoiled silage in two herds, carrion in one herd and poultry litter in another herd. The most important findings in 13 botulism suspected cattle were weak tongue tone, dysphagia, tail paralysis, weak anal reflex and locomotion disturbance (recumbency, incoordination). In addition, salivation, inappetence and decreased or absent rumen motility were the other important findings observed (Table 1).

As shown in Table 1, bradycardia was found in two of the cattle and tachycardia was detected in the four. In one animal, severe vomiting and regurgitation were observed (Fig.1).Of 13 affected cattle, 10 died and 3 survived. In 3 surviving cattle, heart rate was normal and neurological findings were milder (lingual tone slightly weaker, tail and anal reflexes were mildly weak in one and moderately weak in two cattle; salivation and nasal discharge was mild in one animal and none of the animals were recumbent). The 3 cows that healed returned to normal within 2-3 weeks. Five of the cattle that died, survived for $12-72$ hours after the clinical examination and one died 6 weeks after the examination. Four animals were euthanized 4-7 days after the onset of clinical signs due to poor prognosis.

A mouse bioassay test was positive in the rumen content of two heifers from herd B, whereas toxin was not detected in rumen contents collected from other animals and toxin analyzes of feed samples were negative in all herds.

Serum choline, AST, ALT and K levels were higher in the botulismus botulisms group compared to the control group (Table 2). In the correlation analysis in the botulism group and pooled data, choline was positively correlated with total protein and albumin (Table 3). On the other hand, there was a negative correlation between choline and AST in the botulism group (Table 3). In addition, when the biochemical data of botulism cases that survived and died were compared, it was noted that choline levels of the survivors were lower and total protein and phosphorus were higher (Table 4).

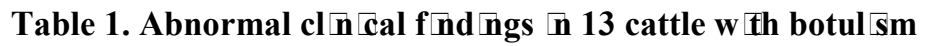

\begin{tabular}{|c|c|c|c|}
\hline Fndng & Varable & Number of cattle & Abnormal fndngs \\
\hline \multicolumn{4}{|c|}{ General examination } \\
\hline \multirow{3}{*}{ Appetite } & Decreased & 4 & 12 \\
\hline & Absent & 8 & \\
\hline & Desire to eat & 1 & \\
\hline \multirow[t]{2}{*}{ Body temperature } & Normal & 13 & 0 \\
\hline & Normal & 7 & \\
\hline \multirow[t]{2}{*}{ Heart rate } & Bradycardia & 2 & 6 \\
\hline & Tachycardia & 4 & \\
\hline \multirow{2}{*}{ Respiratory rate } & Normal & 8 & 5 \\
\hline & High & 5 & 5 \\
\hline \multirow{3}{*}{ Nasal discharge } & Mild & 3 & \\
\hline & Severe & 2 & 5 \\
\hline & Swaying while standing, difficult and ataxic gait & 8 & \\
\hline \multirow[t]{2}{*}{ Locomation } & Sternal recumbency & 4 & 13 \\
\hline & Lateral recumbency & 1 & \\
\hline \multicolumn{4}{|c|}{ Gastrointestinal findings } \\
\hline \multirow{3}{*}{ Ruminal motility } & Normal & 1 & \\
\hline & Reduced & 2 & 12 \\
\hline & Absent & 10 & \\
\hline \multirow{4}{*}{$\begin{array}{l}\text { Vomiting and } \\
\text { regurgitation }\end{array}$} & Severe & 1 & \\
\hline & Absent & 12 & 1 \\
\hline & Neurological findings & & \\
\hline & Mild reduced & 5 & \\
\hline \multirow[t]{2}{*}{ Tongue strength } & Moderately reduced & 6 & 13 \\
\hline & Severely reduced & 2 & \\
\hline \multirow{2}{*}{ Swallowing } & Difficult & 9 & \\
\hline & Could not swallow & 4 & 13 \\
\hline Salivation & Absent & 7 & 6 \\
\hline
\end{tabular}




\begin{tabular}{clcc}
\hline & Mild & 1 & \\
& Moderate & 5 & \\
& Normal & 1 & $\mathbf{1 2}$ \\
\multirow{5}{*}{ Tail tone } & Mild reduced & 1 & \\
& Moderately reduced & 8 & $\mathbf{1 3}$ \\
& Severely reduced & 3 & $\mathbf{1 3}$ \\
\hline
\end{tabular}

Table 2. B ochem cal f nd ngs (Mean \pm SEM) $n$ botul sm and control groups

\begin{tabular}{lccc}
\hline & Botul $\mathbf{s m}$ & Control & $\mathbf{P}$ \\
Chol $\mathbf{n e}(\boldsymbol{\mu m o l} / \mathbf{L})$ & $\mathbf{5 8 . 3} \pm \mathbf{8 . 2}$ & $\mathbf{2 7 . 8} \pm \mathbf{4 . 7}$ & $\mathbf{0 . 0 0 3}$ \\
Total Protein $(\mathrm{g} / \mathrm{L})$ & $7.78 \pm 0.42$ & $7.16 \pm 0.35$ & n.s. \\
Albumin $(\mathrm{g} / \mathrm{L})$ & $3.34 \pm 0.18$ & $3.11 \pm 0.10$ & n.s. \\
ALT $(\mathbf{I U} / \mathbf{L})$ & $\mathbf{4 3 . 1} \pm \mathbf{9 . 7}$ & $\mathbf{2 0 . 3} \pm \mathbf{3 . 1}$ & $\mathbf{0 . 0 2 5}$ \\
AST $(\mathbf{I U} / \mathbf{L})$ & $\mathbf{2 1 8 . 6} \pm \mathbf{3 8 . 5}$ & $\mathbf{8 9 . 3} \pm \mathbf{9 . 6}$ & $<\mathbf{0 . 0 0 1}$ \\
$\mathrm{GGT}(\mathrm{IU} / \mathrm{L})$ & $28.3 \pm 5.5$ & $18.5 \pm 5.5$ & n.s. \\
$\mathrm{Ca}(\mathrm{mg} / \mathrm{dL})$ & $9.04 \pm 0.26$ & $9.21 \pm 0.14$ & n.s. \\
$\mathrm{Mg}(\mathrm{mg} / \mathrm{dL})$ & $2.08 \pm 0.17$ & $2.11 \pm 0.08$ & n.s. \\
P $(\mathrm{mg} / \mathrm{dL})$ & $7.80 \pm 0.56$ & $7.95 \pm 0.36$ & n.s. \\
K $(\mathbf{m g} / \mathbf{d L})$ & $\mathbf{5 . 2 1} \pm \mathbf{0 . 1 4}$ & $\mathbf{4 . 5 7} \pm \mathbf{0 . 1 4}$ & $\mathbf{0 . 0 0 3}$ \\
\hline
\end{tabular}

Table 3. Correlat 0 n between $b$ ochem cal parameters $n$ botul $/ \mathrm{sm}$ group $(n=13)$

\begin{tabular}{|c|c|c|c|c|c|c|c|c|c|}
\hline & TP & Album $n$ & ALT & AST & GGT & $\mathbf{C a}$ & Mg & $\mathbf{P}$ & K \\
\hline Choline & $0.83^{* *}$ & $0.85^{* * *}$ & -0.53 & $-0.63^{*}$ & 0.20 & 0.42 & $0.65^{*}$ & $0.68^{*}$ & 0.51 \\
\hline TP & & $0.95^{* * *}$ & $-0.61^{*}$ & $-0.72^{*}$ & 0.15 & 0.48 & $0.76^{* *}$ & $0.65^{*}$ & 0.29 \\
\hline Albumin & & & -0.51 & $-0.68^{*}$ & 0.05 & 0.55 & $0.78^{* *}$ & 0.52 & 0.23 \\
\hline ALT & & & & $0.93^{* * *}$ & -0.57 & -0.16 & -0.13 & -0.55 & -0.23 \\
\hline AST & & & & & -0.40 & -0.45 & -0.38 & -0.41 & -0.10 \\
\hline GGT & & & & & & -0.03 & -0.12 & 0.31 & 0.21 \\
\hline $\mathrm{Ca}$ & & & & & & & $0.79^{* *}$ & -0.19 & -0.10 \\
\hline $\mathrm{Mg}$ & & & & & & & & 0.16 & 0.01 \\
\hline $\mathrm{P}$ & & & & & & & & & $0.76^{* *}$ \\
\hline
\end{tabular}

Table 4.Compar son of $b$ ochem cal f $\mathrm{nd}$ ngs of surv vors and an mals that d ed

\begin{tabular}{ccc}
\hline & Survvors $(\mathbf{n}=\mathbf{3})$ & Dead $(\mathbf{n}=\mathbf{1 0})$ \\
\hline Chol $\mathbf{n e}(\boldsymbol{\mu m o l} / \mathbf{L})$ & $28.9 \pm 8.4$ & $68.1 \pm 8.45$ \\
$\mathbf{T P}(\mathbf{g} / \mathbf{L})$ & $8.36 \pm 0.6$ & $7.70 \pm 0.5$ \\
$\mathbf{A l b u m} \mathbf{n}(\mathbf{g} / \mathbf{L})$ & $3.4 \pm 0.28$ & $3.25 \pm 0.23$ \\
$\mathbf{A L T}(\mathbf{I U} / \mathbf{L})$ & $26.0 \pm 2.5$ & $49.3 \pm 12.7$ \\
$\mathbf{A S T}(\mathbf{I U} / \mathbf{L})$ & $195.3 \pm 9.8$ & $227.3 \pm 53.4$ \\
$\mathbf{G G T}(\mathbf{I U} / \mathbf{L})$ & $46.3 \pm 15.3$ & $20.5 \pm 4.1$ \\
$\mathbf{C a}(\mathbf{m g} / \mathbf{d L})$ & $8.5 \pm 0.4$ & $9.2 \pm 0.3$ \\
$\mathbf{M g}(\mathbf{m g} / \mathbf{d L})$ & $1.9 \pm 0.2$ & $2.1 \pm 0.2$ \\
$\mathbf{P}(\mathbf{m g} / \mathbf{d L})$ & $9.7 \pm 1.1$ & $7.1 \pm 0.4$ \\
$\mathbf{K}(\mathbf{m g} / \mathbf{d L})$ & $5.5 \pm 0.2$ & $5.1 \pm 0.1$ \\
\hline
\end{tabular}




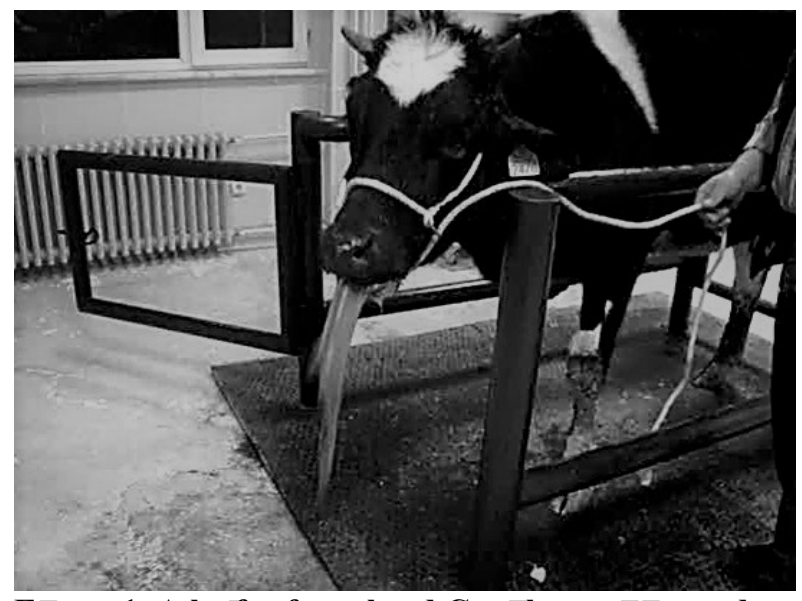

F gure 1. A he fer from herd $\mathrm{C} w$ th vom $t$ ng and regurg tat on.

\section{DISCUSSION}

Outbreaks of botulism are reported in cattle worldwide. Reported sources of botulinum toxin are spoiled silage contaminated with $\mathrm{Cl}$. botulinum (Yeruham et al., 2003), animals eating carrion or feedstuff contaminated with carrion associated toxin (Galey et al., Barel et al., 2016). It has also been reported that poultry litter is an important source of toxin in ruminant botulism cases (Radostits et al., 2007, Souillard et al., 2015, Relun et al. 2017), and that roughage contaminated with poultry litter could also be a source for botulism (Souillard et al., 2017). In the present study, it was observed that silage was the probable source of toxin in two herds, carrion in one herd and poultry litter in one herd.

The diagnosis of botulism in cattle is mostly made based on clinical findings. In this study, botulism toxin was determined from rumen samples of only two cattle from one out of 4 four herds. Botulism toxin is so rapidly denatured (Martin, 2003) or is found at very low levels in samples (Galey et al., 2000), hence it is often not possible to detect toxin in botulism cases. In accordance with our findings, Braun et al. (2005) were able to detect botulism toxin in only 4 animals from 1 herd out of 11 herds.

The main action of BoNT is to prevent the fusion of synaptic vesicles with the plasma membrane of nerve endings resulting with inhibition of neurotransmitter release, in particular acetylcholine from the axon endings (Simpson, 2004). Halted neurotransmitter release causes flaccid paralysis which is characterized by clinical findings such as sudden paralysis starting from hind limbs affecting also the tail, inability to retract tongue and recumbency in later stages. Decreased contractility of tongue, dysphagia, paralysis of the tail, decreased anal reflexes and locomotion disorder were the main clinical findings observed in our study. Braun et al. (2005) observed decreased tonus of tongue and ruminal motility along with dysphagia and hyper salivation as important findings of botulism in cattle. On the other hand, they reported inappetence in half of the animals and decreased appetite in the other half. In the present study we observed complete inappetence in 8 animals, decreased appetite in two and, despite a desire to eat, inability to swallow in one animal. Senturk and Cihan (2007) also reported decreased tongue tone, dysphagia, weak tail tone, weak anal reflex, decreased or absent ruminal motility and decreased or absent appetite in all 26 cattle suffering from botulism. Similar findings were observed in two other studies (Sharpe et al., 2008; Aytekin et al., 2016); however weak tongue tonus was not the main finding in the report of Sharpe et al. (2008). While regurgitation and vomiting were not reported in these three studies, vomiting and regurgitation was detected in a cow in our study. As a matter of fact, vomiting and regurgitation have been reported in botulism type B cattle with feed originated toxication (Bruckstein and Tromp, 2001). The suspected source of toxin of the animal vomiting and regurgitating was silage. It has also been reported that in botulism associated with type $\mathrm{B}$, there is no recumbency or paralysis and muscle weakness in the hind limbs (Bruckstein and Tromp, 2001). Parallel to this observation, it was noticed that one of the animals from that herd had vomiting and regurgitation and the other had significant tongue paralysis however weakness in the hind limbs and recumbency was not observed in this animas (Fig. 1).

While bradycardia was detected in 2 cattle and tachycardia in 4 cattle in our study, Senturk and Cihan (2007) detected bradycardia in 18 of 26 cases, whereas Braun et al. (2005) detected bradycardia in 8 of the 30 cases and tachycardia in 8 . In the present study, three of the animals with normal heart rates survived. In other studies, the abnormal heart rates were associated with higher mortality rate (Braun et al., 2005; Senturk and Cihan, 2007). It was observed that the clinical findings of the 3 surviving cattle from the herd A were mild. Indeed, many studies reported low survival rates of botulism in cattle (Martin, 2003). However, parallel with our findings Braun et al. (2005) reported that 13 out of 30 cattle with milder signs suriveved survived and also reported that none of thesurivors survivors were recumbent, heart rates were within reference ranges and tongue tone was weak in only two of the survivors. It is reported that the mortality rate is very high in severe botulism cases (Braun et al., 2005; Senturk and Cihan, 2007) and even herd mortality rate of up to $98 \%$ is reported (Holzhauer et al., 2009).

In addition to typical neuromuscular findings, Böhnel et al. (2001) reported a different form of botulism called 'visceral botulismus' characterized with findings such as increased respiratory rate, laminitis, decreased rumen motility, constipation and diarrhea. In the present study, it was determined that the motility of the rumen was 
decreased or absent in 12 of 13 cattle. Also, the respiration rate was high in 5 of 13 animals. These findings indicate that along with typical neuromuscular findings, general and gastrointestinal findings consistent with the definition of visceral botulism could be detected. Along with that AST $(\mathrm{P}<0.001)$, ALT $(\mathrm{P}<0.025)$ and $\mathrm{K}(\mathrm{P}<0.003)$ levels were higher in cattle suffering from botulism. Increased AST and K levels could be associated with recumbency associated rhabdomyolysis. Increased ALT levels could also be associated with rhabdomyolysis since Nathwani et al. (2005) reported that along with AST, ALT levels also increases in case of acute muscular damage. Ten cattle suffering from botulism were recumbent at the time of examination in our study. Due to the high body weight of the species, even short periods of recumbency could result with ischemia of muscles in cattle. Thus elevated AST, ALT and $\mathrm{K}$ levels in the botulism group are probably associated with muscular damage. On the other hand, as AST and GGT levels were increased, elevated ALT levels could also be associated with liver damage. Indeed, Aytekin et al. (2016) reported low ALT and normal AST levels in cattle suffering from botulism.

Serum choline levels were significantly higher in the botulism group when compared to the healthy animals. Klein et al. (1993) reported that hypoxic conditions cause activation of phospholipase A2 leading to release of free choline from choline containing phospholipids. Similarly Korth et al. (2000) detected elevated extracellular choline levels in tourniquet induced human skeletal muscle ischemia. Muscle ischemia is a possible cause of the elevated choline levels in the botulism group as AST, ALT and $\mathrm{K}$ levels were also higher. However choline levels were not correlated with AST, ALT and K levels in the pooled data and interestingly AST was negatively correlated with choline in the botulism group. Thus a mechanism other than muscle damage could be responsible for the elevated choline levels in the botulism group.

In the light shed by previous reports, it may be hypothesized that inhibition of acetylcholine release from nerve endings in botulism could trigger a feedback for inhibiton inhibition of choline uptake and acetylcholine synthesis resulting in accumulation of free choline. This hypothesis is supported in part by studies reporting reduced activity of choline acetyltransferase (CAT) enzyme during botulism (Ekström et al., 1977) which may prevent choline incorporation into acetylcholine. In addition, BoNT A was shown previously to inhibit synaptosomal choline uptake (Gundersen and Howard, 1978; Habermann et al., 1981). Hence, the elevated choline levels observed in cattle suffering from botulism in our study could be associated with decreased uptake and utilization of choline in tissues thereby leading to its accumulation.

In conclusion, clinical findings such as decreased contractility of tongue, dysphagia, tail paralysis, decreased anal reflexes and locomotion disorders are of significant value for diagnosis of botulism in cattle. In addition, cattle with mild clinical signs have higher chance of survival which is probably associated with and lower choline levels have higher chance of survival. Although the exact mechanism of elevated choline levels could not be explained, to our knowledge this is the first study evaluating serum choline levels in cattle suffering from botulism. Further studies are warranted that could reveal the pathophysiological role of choline in botulism cases.

Confl ct of nterest: Authors did not declare any conflict of interests

\section{REFERENCES}

Aytekin, I., F. Kaya, and H. Atalay (2016). Evaluation of serum haptoglobin, ceruloplasmin and pseudocholinesterase levels in cows with botulism. Kafkas Univ. Vet. Fak.22: 367-371.

Barel, S., D. Elad, O. Cuneah, M. Massrwa, and J.A. Shimshoni (2016). Common feed and animal derived food contaminants in Israel. Isr. J. Vet. Med. 71: 3-13.

Blusztajn, J.K. (1998). Choline, a vital amine. Science 281:794-795.

Böhnel H., B. Schwagerick, and F. Gessler (2001). Visceral botulism a new form of bovine Clostridium botulinum toxication. J. Vet. Med. A. Physiol. Pathol. Clin. Med. 48: 373-383.

Braun, U., K. Feige, G. Schweizer and A. Pospischil (2005).Clinical findings and treatment of 30 cattle with botulism. Vet. Rec. 156: 438-441.

Bruckstein, S., and A.M. Tromp (2001). Food poisoning in three family dairy herds associated with Clostridium botulinum type B. Isr. J. Vet. Med. 56: 95-100.

Cansev, M., F. Orhan, E.O. Yaylagul, E. Isik, M. Turkyilmaz, S. Aydin, A. Gumus, C. Sevinc, N. Coskun, I.H. Ulus, and R.J. Wurtman (2015). Evidence for the existence of pyrimidinergic transmission in rat brain. Neuropharmacology. 91: 77-86.

Cohen, E.L., and R.J. Wurtman (1976). Brain acetylcholine: control by dietary choline. Science. 191: 561-562.

Cohen, E.L., and R.J. Wurtman (1975). Brain acetylcholine: Increases after systemic choline administration. Life Sci. 16: 1095-1102.

Ekström, J., S. K. Kemplay, J. R. Garrett, and L. W. Duchen (1977). Effect of botulinum toxin on the 
choline acetyltransferase activity in salivary glands of cats. Experientia. 33: 1458-1460.

Galey, F.D., R.Terra, R. Walker, J. Adaska, M.A. Etchebarne, B. Puscher, E. Fisher, R.H. Whitlock, T. Rocke, D. Willoughby, and E. Tor (2000). Type C botulism in dairy cattle from feed contaminated with a dead cat. J. Vet. Diagn. Invest. 12: 204-209.

Gundersen, C.B. and B.D. Howard (1978). The effects of botulinum toxin on acetylcholine metabolism in mouse brain slices and synaptosomes. J. Neurochem. 31: 1005-1013.

Habermann, E., H. Bigalke, and I. Heller (1981). Inhibition of synaptosomal choline uptake by tetanus and botulinum a toxin. Naunyn Schmiedebergs Arch. Pharmacol.316: 135142.

Holzhauer, M., H. I. Roest, M. G. de Jong and J. H. Vos (2009). Botulism in dairy cattle in 2008: symptoms, diagnosis, pathogenesis, therapy, and prevention. Tijdschr Diergeneeskd. 134: 564-570.

Klein, J., T. Holler, E. Cappel, A.Köppen, K. Löffelholz (1993). Release of choline from rat brain under hypoxia: contribution from phospholipase A2 but not from phospholipase D. Brain Res. 630: 337-40.

Korth, U., G. Merkel, F.F. Fernandez, O. Jandewerth, G. Dogan, T. Koch, K. Van Ackern, O., O. Weichel, and J. Klein (2000). Tourniquetinduced changes of energy metabolism in human skeletal muscle monitored by microdialysis. Anesthesiology 93: 1407-1412.

Martin, S. (2003). Clostridium botulinum type D intoxication in a dairy herd in Ontario. Can. Vet. J. 44: 493-495.

Mawhinney, I., D. Palmer, F. Gessler, M. Cranwell, L. Foyle, A. Otter, J. Payne, and B. Strugnell (2012). Investigation of serology for diagnosis of outbreaks of botulism in cattle. Vet. J. 192: 382-384.

Nathwani, R.A., S. Pais, T.B. Reynolds, and N. Kaplowitz (2005). Serum alanine aminotransferase in skeletal muscle diseases. Hepatology 41: 380-382.

Otter, A., C.Livesey, R.Hogg, R.Sharpe, and D. Cray (2006).Risk of botulism in cattle and sheep arising from contact with broiler litter. Vet. Rec. 159: 186-187.

Popoff, M.R. (2014). Botulinum neurotoxins: More and more diverse and fascinating toxic proteins. J. Infect. Dis. 209: 168-169.
Radostits, O.M., C.C. Gay, K.W. Hinchcliff, and P.D. Constable (2007). Botulism In: Veterinary Medicine, 10th ed. London: WB Saunders;. 824$828 \mathrm{p}$.

Relun, A., L. Dorso, A. Douart, C. Chartier, R. Guatteo, C. Mazuet, M. R. Popoff, S. Assié (2017). A large outbreak of bovine botulism possibly linked to a massive contamination of grass silage by type $\mathrm{D} / \mathrm{C}$ Clostridium botulinum spores on a farm with dairy and poultry operations. Epidemiol Infect. 145: 3477-3485.

Scarlatos, A., B. A. Welt, B. Y. Cooper, D. Archer, T. De Marse, and K.V. Chau (2005). Methods for detecting botulinum toxin with applicability to screening foods against biological terrorist attacks. J. Food Sci. 70: 121-130.

Senturk, S., and H. Cihan (2007). Outbreak of botulism in a dairy herd in Turkey. Ir. Vet. J. 60:481-484.

Sharpe, A.E., C.P. Brady, W. Byrne, J. Moriarty, P. O'Neill, and J. G. McLaughlin (2008). Major outbreak of suspected botulism in a dairy herd in the Republic of Ireland. Vet. Rec. 162: 409-412.

Simpson, L.L. (2004) Identification of the major steps in botulinum toxin action. Annu. Rev. Pharmacol. Toxicol.44: 167-193.

Souillard, R., C. Le Maréchal, F. Hollebecque, S. Rouxel, A. Barbé, E. Houard, D. Léon, T. Poëzévara, P. Fach, C. Woudstra, F. Mahé, M. Chemaly, S. Le Bouquin (2015) Occurrence of $C$. botulinum in healthy cattle and their environment following poultry botulism outbreaks in mixed farms. Vet Microbiol. 180:142-145.

Souillard, R., C. Le Maréchal, V. Ballan, F. Mahé, M. Chemaly, and S. Le Bouquin (2017). Bovine botulism outbreak associated with a suspected cross-contamination from a poultry farm. Vet. Microbiol. 208: 212-216.

Wurtman, R.J., M. Cansev, and I.H. Ulus (2009). Choline and its products acetylcholine and phosphatidylcholine. In: Lajtha A, editor. Handbook of Neurochemistry and Molecular Neurobiology. Springer-Verlag;. 443-501 p.

Yeruham, I., D. Elad, Y. Avidar, K. Grinberg, D. Tiomkin, and A. Monbaz (2003). Outbreak of botulism type $B$ in a dairy cattle herd: clinical and epidemiological aspects. Vet. Rec. 153: 270-272.

Zeisel, S.H. (1992) Choline: an important nutrient in brain development, liver function and carcinogenesis. J. Am. Coll. Nutr. 11: 473-481. 